3. Australian Bureau of Statistics. Women's Safety Australia 1996. Canberra: ABS, 1996.

4. James M, Hallinan J. Homicides in Australia 1992-93. Trends \& Issues, No. 51, Aust Institute of Criminology, 1995.

5. NSW Health Department. NSW Health Survey 1994.

6. Alpers P, Morgan B. Firearm Homicide in New Zealand:
Victims, perpetrators and their weapons 1992-94. Paper presented at the National Conference of the Public Health Association of New Zealand, Dunedin, 28 June 1995.

7. De Moore GM, Plew JD, Bray KM, Snars JN. Survivors of self-inflicted firearm injury: A liaison psychiatry perspective Med J Aust 1994; 160: 421-5. W

\title{
CHILDHOOD INJURY SURVEILLANCE: THE VALUE OF EMERGENCY DEPARTMENT DATA
}

\author{
Meredith Nirui, Valerie Delpech, Mark Ferson \\ South Eastern Sydney Public Health Unit

\section{Linda Christie} \\ South Eastern Sydney Area Health Service
}

This article examines child injury data from the Sydney Children's Hospital Emergency Department database for an 11-month period. The database provides useful local information about the nature, location and type of injuries sustained by children that is essential for effective local planning of injury prevention initiatives.

\section{INTRODUCTION}

Injury has been identified as a priority area for the health system at all levels. It is a leading cause of premature death in Australia and was the fourth highest cause of mortality in NSW in 1994. ${ }^{1}$ From 1991 to 1995 , injury was the third leading cause of hospital separations among South Eastern Sydney (SES) residents, representing eight per cent of admissions. ${ }^{2}$ However, mortality and inpatient data describing injury are limited. The emergency department (ED) is an appropriate setting to study the location of injuries on the body and where the event took place.

Despite a number of initiatives at state and national levels, there is currently no consistent approach to the collection of injury data by emergency departments. In 1990 the National Injury Surveillance Unit (NISU) of the Australian Institute of Health and Welfare introduced the Injury Surveillance Information System (ISIS) to collate data on ED injury presentations at a national level. While ISIS data provided a better understanding of the context of injuries, it was labour-intensive and implemented in a nonrepresentative sample of 50 hospitals. Therefore, it was not able to provide incidence rates. In 1996, the NSW Department of Health introduced the Emergency Department Information System (EDIS). This involves recording of ED presentations electronically. At this stage EDIS has been implemented in an abbreviated form and in a limited number of EDs across NSW.
To assess the completeness and value of the EDIS database and thus its potential to contribute to the study of childhood injuries, we examined the EDIS injury data (January-November 1996) collated by the Sydney Children's Hospital, the major paediatric referral hospital serving the south eastern area of Sydney. During the 1996 calendar year, 21 per cent of all ED presentations at the Sydney Children's Hospital were due to injury.

\section{METHODS}

Between January and November 1996, parents of children up to the age of 15 years presenting with an injury to the ED of the Sydney Children's Hospital were asked to complete a detailed questionnaire including their demographics and information on the injury sustained. The data were entered into the EDIS database by an Injury Surveillance Officer. Completeness of the data was largely dependent upon parental consent and cooperation and is estimated to be 80 to 85 per cent complete. Data were analysed by gender, age group ( 0 to 4 years, 5 to 9 years and 10 to 14 years), cause, place, and type of injury, using SPSSv8 for Windows and Epi-Info v6. Severity of injury was assessed using E-codes.

\section{RESULTS}

Over the 11-month study period, data on 2549 children (1006 girls, 1543 boys) up to age 15 were recorded in the EDIS injury database. Children aged 0 to 4 years accounted for 38 per cent of presentations, compared to 35 per cent and 27 per cent in the 10 to 15 years and 5 to 9 years age groups, respectively (mean $=7$ years). The male to female ratio for all ages was 1.5:1. More boys were represented in all age groups, but a significant higher proportion of boys presented among 10 to 15 year olds (male to female ratio $=1.9: 1, \mathrm{OR}=1.43, \mathrm{CI}=1.20-1.69$ ).

\section{Cause of injury}

More than half of injury presentations were due to falls (Table 1). Younger age groups were more likely to present with a fall $(\mathrm{p}=0.02)$. Falls from low height falls $(<1$ metre or same level) accounted for the majority (88.4 per cent) of 


\section{TABLE 1}

\section{CAUSE OF INJURY, BY AGE GROUP}

\begin{tabular}{|c|c|c|c|c|c|c|c|c|}
\hline \multirow{2}{*}{$\begin{array}{l}\text { Age group } \\
\text { Type of Injury }\end{array}$} & \multicolumn{2}{|c|}{$0-4$ years } & \multicolumn{2}{|c|}{ 5-9 years } & \multicolumn{2}{|c|}{$10-14$ years } & \multicolumn{2}{|c|}{ Total } \\
\hline & $\mathrm{n}$ & $\%$ & $\mathrm{n}$ & $\%$ & $\mathrm{n}$ & $\%$ & $\mathrm{n}$ & $\%$ \\
\hline Falls & 573 & 56.3 & 380 & 54.7 & 421 & 46.7 & 1338 & 52.5 \\
\hline Low fall $(<1 \mathrm{~m})$ & 470 & 49.3 & 309 & 44.5 & 404 & 44.8 & 1183 & 46.4 \\
\hline High fall ( $\geq 1 \mathrm{~m})$ & 67 & 7.0 & 71 & 10.2 & 17 & 1.9 & 155 & 6.1 \\
\hline Struck by object & 148 & 15.5 & 155 & 22.3 & 276 & 30.6 & 579 & 22.7 \\
\hline Cut/piercing object & 48 & 5.0 & 50 & 7.2 & 60 & 6.7 & 158 & 6.2 \\
\hline Scald or burn & 35 & 3.7 & 11 & 1.5 & 8 & 0.9 & 54 & 2.2 \\
\hline Pedal cycling & 8 & 0.8 & 20 & 2.9 & 25 & 2.8 & 53 & 2.1 \\
\hline Animal related & 13 & 1.4 & 20 & 2.9 & 17 & 1.9 & 50 & 2.0 \\
\hline Poisoning & 21 & 2.2 & 0 & 0.0 & 1 & 0.1 & 22 & 0.9 \\
\hline Motor vehicle & 5 & 0.5 & 3 & 0.4 & 9 & 1.0 & 17 & 0.8 \\
\hline Pedestrian & 4 & 0.4 & 6 & 0.9 & 8 & 0.9 & 18 & 0.7 \\
\hline Fire, flames or smoke & 1 & 0.1 & 1 & 0.1 & 3 & 0.3 & 5 & 0.2 \\
\hline Near drowning & 1 & 0.1 & 0 & 0.0 & 1 & 0.1 & 2 & 0.1 \\
\hline Other specified cause & 116 & 12.0 & 46 & 6.6 & 67 & 7.4 & 229 & 8.5 \\
\hline Other or unspecified & 16 & 1.7 & 3 & 0.4 & 5 & 0.6 & 24 & 0.9 \\
\hline Total & 953 & 100.0 & 695 & 100.0 & 901 & 100.0 & 254 & 100.0 \\
\hline
\end{tabular}

Data source: Sydney Children's Hospital, EDIS (January-November 1996).

\begin{tabular}{|c|c|c|c|c|c|c|c|c|}
\hline \multicolumn{9}{|c|}{ PLACE OF INJURY, BY AGE GROUP } \\
\hline \multirow{2}{*}{$\begin{array}{l}\text { Age group } \\
\text { Place of injury }\end{array}$} & \multicolumn{2}{|c|}{$0-4$ years } & \multicolumn{2}{|c|}{$5-9$ years } & \multicolumn{2}{|c|}{$10-15$ years } & \multicolumn{2}{|c|}{ Total } \\
\hline & $\mathrm{n}$ & $\%$ & $\mathrm{n}$ & $\%$ & $\mathrm{n}$ & $\%$ & $\mathrm{n}$ & $\%$ \\
\hline Home & 679 & 58.2 & 314 & 26.9 & 173 & 14.8 & 1166 & 45.7 \\
\hline School & 11 & 1.1 & 138 & 19.9 & 225 & 25.0 & 374 & 14.7 \\
\hline Sporting area & 5 & 0.5 & 32 & 4.6 & 187 & 20.7 & 224 & 8.8 \\
\hline Park/playground & 57 & 6.0 & 70 & 10.8 & 87 & 9.7 & 217 & 8.6 \\
\hline Road & 20 & 2.1 & 33 & 4.7 & 59 & 6.5 & 112 & 4.4 \\
\hline Footpath & 23 & 2.4 & 26 & 3.7 & 56 & 6.2 & 105 & 4.4 \\
\hline Child care/kindergarten & 60 & 6.3 & 7 & 1.0 & - & - & 67 & 2.7 \\
\hline Beach/ocean & 14 & 1.5 & 14 & 2.0 & 37 & 4.1 & 65 & 2.6 \\
\hline Public swimming pool & 2 & 0.2 & 9 & 1.3 & 15 & 1.7 & 26 & 1.0 \\
\hline Other/unknown & 72 & 7.5 & 52 & 7.5 & 62 & 6.9 & 186 & 7.3 \\
\hline Total & 953 & 100.0 & 695 & 100.0 & 901 & 100.0 & 2549 & 100.0 \\
\hline
\end{tabular}

fall presentations; however, younger children ( $<10$ years) were more likely to present with falls from greater heights ( $\geq 1$ metre $),(\mathrm{OR}=4.21),(\mathrm{CI}=2.45-7.33)$. There was no significant difference between boys and girls.

Other causes of injury included: being struck by an object (22.7 per cent); cuts and piercings (6.2 per cent); scalds and burns (2.2 per cent); pedal cycling (2.1 per cent); and animal related accidents (2.0 per cent). Poisonings represented less than one per cent of injuries; however, 21 of 22 (95 per cent) reported poisonings were to children aged 0 to 4 years. Five children ( 0.2 per cent) had injuries related to fire or smoke exposure and two ( 0.08 per cent $)$ presented following incidents of near-drowning.
More than eight per cent of injuries were reported as 'other specified cause'. More than half of these were injuries due to accidental pulling or twisting of a limb during play or by an adult (four per cent of all injuries) and a quarter were associated with a foreign body in the eye, ear, nose or throat (two per cent of all injuries). Fewer than one per cent of causes of injury were unspecified or missing.

\section{Place of injury}

The home environment was the most frequently reported place of injury and was identified in 45.7 per cent of presentations (Table 2). Younger children were more likely to sustain injuries at home $(\mathrm{p} \leq 0001)$. Within the home the 
living room and garden/yard were the two main danger areas, representing 34.8 per cent and 21.4 per cent of home injuries, respectively. Of home injuries, 9.7 per cent occurred in the kitchen, while 4.3 per cent happened on the stairs. More than 45 per cent of children aged 10 to 15 years sustained their injury at school or on a sporting field. Park and playground accidents accounted for 8.7 per cent of injuries and road accidents 4.4 per cent. Only 18 presentations ( 0.7 per cent) had an unspecified place for the injury.

\section{Severity of injury}

The most common diagnoses associated with an injury were open wounds ( 25.5 per cent), fractures (18.2 per cent), sprains and strains (13.2 per cent) and contusions (15.1 per cent). Open wounds were more frequent among younger children, while older children were more likely to present with a fracture. There were no significant differences between boys and girls. The majority (91 per cent) of children were discharged by the ED, 193 (7.5 per cent) required admission to an inpatient ward and four ( 0.2 per cent) were admitted and discharged through the ED. No deaths were reported on the EDIS database.

\section{DISCUSSION}

We believe that the ED injury database provides useful information about the nature, location and type of injuries sustained by children. Unfortunately, the data were limited to an 11-month period, and we were not able to predict the pattern and burden of childhood injuries or to compare these with other NSW health areas or other states.

Falls were the single most important cause of injury presentation across all age groups; however, falls from heights greater than one metre were more frequently seen in younger children. Being struck by an object and cuts were also significant causes of injury presentation. More than a quarter of children who present to the ED as a result of an injury are treated for open wounds and almost one in five for a bone fracture. Approximately one in 10 required hospitalisation. Welcome observations included few reported (pedal) cycle accidents, scalds or poisonings. Consideration should be given to including data fields such as 'pulling or twisting of limb' and 'insertion of foreign body', which account for a significant proportion of injury presentations.

As reported by previous researchers, ${ }^{3}$ the home environment is the most common setting for childhood injuries. This is not surprising because younger children in particular spend the majority of their time at home. Other common places of injury were the school and sporting fields for older children, and child-care centres for younger children. Attention should be given to raising awareness among parents and professionals of ways to reduce injuries in the home and at other common places of injury. It would be feasible for injury professionals, local council staff and the regulatory agency (in NSW, the Department of Community Services) to monitor safety and injury in public facilities. Education programs could also direct caregivers to seek help and to assist professionals in developing and initiating prevention strategies. Much work has been done on the safety of playground equipment and on addressing the lack of uniform standards for monitoring that equipment. ${ }^{5,6}$

Injury prevention strategies should be based on epidemiological evidence. Injury control depends on reliable and consistent data. There is currently a lack of adequate surveillance data, particularly at the ED level. Supporting NISU to develop and implement a national injury surveillance database will contribute to a better understanding of problems and provide baseline data to support the development and implementation of evidencebased injury prevention control programs.

\section{ACKNOWLEDGMENTS}

We would like to thank Ms Mindy Xie and Ms Anne Ryan from SESAHS and Mr Stan Bordeaux and Dr James Harrison of NISU for their comments. We are also grateful to Ms Robyn Barnes and Ms Lauren Booth of the SESPHU for their assistance.

\section{REFERENCES}

1. Australian Institute of Health and Welfare and Commonwealth Department of Health and Family Services. First report on national health priority areas 1996. Canberra: Australian Institute of Health and Welfare, 1997.

2. South Eastern Sydney Area Health Service. Population Health Profile, 1997. Dolls Point, 1998.

3. Adesunkanmi AR, Oginni LM, Oyelami AO, Badru OS. Epidemiology of childhood injury. J. Trauma 1998; 44: 506512.

4. Mulligan SD, Puranik S, Coffman S. Parental perception of injury prevention practices in a multicultural metropolitan area. Pediatric Emergency Care 1998; 14: 10-14.

5. Kidsafe NSW, NSW Health Department. NSW local government playground safety study. October 1995.

6. Kidsafe NSW, NSW Health Department. Phase II: Recommended action plan following the NSW local government safety study. October 1996 . 